Published as: North, S., and Oliver, J.J., (2014). A strategic look at how to extend your digital footprint, Strategic Direction, Vol. 30 Iss: 7, pp.1-3

Title: A strategic look at how to extend your digital footprint

Abstract

Purpose: To provide an overview of the key strategic questions that need to be considered when evaluating whether or not to extend a company's reach across multiple digital platforms.

Design/methodology/approach: The viewpoint presented in this paper reflects both the practical experience of conceiving, launching and implementing a multi-platform digital strategy, combined with an academic insight into branding and strategic resource allocation and management.

Findings: Before extending your digital footprint, executives need to consider several key questions that will impact on the relative success of their digital strategy.

Practical implications: A digital strategy that extends a company's reach across multiple platforms needs to be considered in terms of delivering against corporate and business level strategy in order to be effective.

Originality/value: A unique combination of practical experience fused with academic knowledge on the key questions that should be considered in order to successfully design and implement a multi-platform digital strategy.

Keywords: Digital Media, Online Marketing, Digital Distribution, Multi-platform, Brand Building, Customer Relationship Management 
Published as: North, S., and Oliver, J.J., (2014). A strategic look at how to extend your digital footprint, Strategic Direction, Vol. 30 Iss: 7, pp.1-3

\section{A strategic look at how to extend your digital footprint}

The digital revolution has changed the way many firms have run their businesses over the past decade. The digital space offers an array of opportunities, many of which are difficult to evaluate, and firms are under increasing pressure to ensure that their brand exists on as many digital platforms as possible. This article presents the key strategic questions that you need to consider when evaluating whether or not to extend your online marketing activity across multiple digital platforms.

\section{What is the objective behind extending your digital footprint?}

There is a strong argument to say that your brand needs to be on numerous digital platforms in order to be seen as contemporary and relevant to customers. However, you need to clearly define your objectives for doing so. Is your objective about helping you to innovate, engage customers, drive cost efficiencies, and increase sales or future proofing your business? These are all clear reasons to extend your digital distribution footprint, but unless you have worked out the motivation for your company, then don't do it. It will end up an expensive mistake both financially and in terms of your corporate reputation.

2. Are you thinking about the technology or the customer?

There is a danger that you start to do things 'because you can'. It's easy to fall into the trap of being drawn into the hype that new technology brings, but it doesn't mean you should use it, especially if your customers aren't going to. A digital platform is the same as any other medium. To get the most out of it, you need to think about your customer first, and then the digital platform. How you can best serve them, attract their loyalty, communicate with them and motivate them? You need to understand whether your audience is engaging with digital media, and if so, where and how often.

3. Are you thinking about the technology or your brand?

As well as thinking about your customer, don't forget what works for your brand, its values and assets. This should be an equally important voice in deciding the digital platform that will help you meet your objective. Understanding your own brand and what is important for it should guide all your online marketing activities. Digital initiatives are always best when they feel like a natural extension of what you are doing rather than a 'bolt on'.

Consider what your brand values are, what makes your brand special, what differentiates your brand from the competition and how you can best build your brand using digital media. Using a digital platform that feels true to your brand will strengthen its impact and therefore the decision to invest in it and the content it provides. This ensures that the overall brand tone of voice and personality are consistent.

4. Are you being pressured into jumping on the digital media bandwagon?

We all feel the pressure to keep up with our competitors. Clearly the last thing you want to do is give a rival a competitive advantage, and then allow them to continue to exploit that 
Published as: North, S., and Oliver, J.J., (2014). A strategic look at how to extend your digital footprint, Strategic Direction, Vol. 30 Iss: 7, pp.1 - 3

advantage unchallenged. But don't be afraid to be second to market. It's not necessarily the worst place to be. When you look at the spectacular decline of MySpace you can see that the digital media environment can change at an alarming pace. Consumers have shown they are willing to move from one digital platform to another with little or no loyalty to an established brand.

So the message is be careful with new digital media initiatives. As it almost always does, it comes back to your customer - know where they are and where they are going. Are they using a particular platform yet? Will they ever? Less can be more, especially when deciding on whether to employ digital devices or platforms. The last thing you want as a business is to back the wrong horse and end up with a large amount of sunk costs.

5. Can you implement your digital media strategy properly?

One of the pitfalls in 'going digital' is that companies don't fully think through the ramifications of their strategy. The concern is that your attention will become fragmented and lead to directing resources away from the route that maximises their performance in the market place. Consequently this can cause your digital strategy to fail due to a lack of focus. You can quickly lose sight of your core objective and over-arching strategy simply because you don't have the resource to implement wide reaching digital media initiatives.

How damaging will it be for your brand if you create a poor product or half your consumers can't use it because it doesn't work on their device?

6. Will your digital media strategy deliver against your corporate or business level strategy?

When you are dealing with any new initiative you need to ensure you have a clear understanding of your strategy and then implement ideas that deliver against it. Working in the digital media environment doesn't change this. The best way to deliver your corporate or business level strategy may be by extending your digital distribution footprint, but there is always a balance to be struck between taking advantage of short term opportunities and focusing on your long term objectives. If extending your digital footprint isn't going to add value to your long term goals, then you must question whether it is something you should be investing time, money and resource into.

7. Is your creativity coming from the technology or the idea?

If the only thing creative about your online marketing project is the fact that it exists on a digital platform, then you need to question its value. This doesn't mean you can't be creative with the choice of digital platform you employ; it just can't be at the expense of the idea itself. Consumers are smart and demanding, not just of new technologies, but of the content it can give them.

The fact that you have a website, an App or a blog isn't enough. If it doesn't have original content that has value, and can engage consumers, then it will not attract users however contemporary it may be. 
Published as: North, S., and Oliver, J.J., (2014). A strategic look at how to extend your digital footprint, Strategic Direction, Vol. 30 Iss: 7, pp.1-3

\section{Does your digital media strategy emphasise continual customer engagement?}

Your customers will expect a continuous delivery of content through digital platforms. You can't just use a digital platform when it suits you. Once you have given your customers a taste, if it works, they will want more and if you don't provide this they will quickly disappear.

So, rather than one big roll out of a new idea, you need to plan continual investment over a long period of time that will keep your customers engaged and interested. Know where you are going with any particular initiative, where you want to take your customer and how you can continue to feed that initiative.

9. Can you integrate your digital media strategy into your core business processes?

You need to ensure that your brand has a consistent identity and set of values across all platforms - traditional and digital. The best way to achieve this is to fully integrate your digital teams into your core business and processes. You can't have them working in a separate unit, simply because there is a danger that they will end up competing with your core business. If the digital team sees the easiest ways to recruit customers is from your traditional platforms, then not only are you limiting the additional benefit new digital initiatives can bring, you are going to waste huge amounts of time, energy and resource just moving your customers from one place to another without adding any value to your company.

Author Details

Steve North, General Manager (Dave and Gold), UKTV, London, England

John Oliver, Associate Professor, Bournemouth University, England. T: +44 (0)1202 965319

E: joliver@bournemouth.ac.uk

Author Biographies

Steve North is a General Manager at UKTV, a multi-award winning media company known for their innovative and brand defining programming. He was responsible for creating the company's most innovative channel brand (Dave) and implementing a multi-platform digital strategy that has contributed to increased market share and corporate revenues.

Dr John Oliver is an Associate Professor of Media Management, and an experienced academic who is published in international management journals. As Deputy President of the European Media Management Association he co-ordinates and supports the association's activities across many European countries. He is also the Programme Director for the Professional Doctorate in the Creative Industries at Bournemouth University. 